\title{
Surgical Techniques and Risk of Postoperative Recurrence in CD: A Game Changer?
}

\author{
Gaetano Luglio ${ }^{a}$ Toru Kono ${ }^{b}$ \\ aDepartment of Medical and Surgical Gastrointestinal Diseases, Endoscopic Surgery Unit, School of Medicine, \\ University of Naples Federico II, Naples, Italy; ${ }^{\text {b} A d v a n c e d ~ S u r g e r y ~ C e n t e r, ~ S a p p o r o ~ H i g a s h i ~ T o k u s h u k a i ~ H o s p i t a l, ~}$ \\ Sapporo, Japan
}

\section{Keywords}

Kono-S anastomosis · Crohn's disease recurrences · Early surgery · Crohn's disease

\begin{abstract}
Background: Since its first description, the role of surgery in Crohn's disease (CD) has always been controversial; in fact, it has been mainly considered as a gastroenterological disease for long time. Nevertheless, despite great advances in medical therapy, up to $70-80 \%$ of patients with CD will require surgery in their lifetime and up to $30 \%$ of them will undergo repeated surgeries due to recurrences. For these reasons, the idea of surgery as a tool in the therapeutic armamentarium to consider even in the early stage of the disease has progressively spread in the last decades, even corroborated by reports showing how primary surgery is able to definitively treat around half of the patients at long-term followup. More surgeons are nowadays more and more involved in developing techniques to reduce recurrences that have always been considered as part of the natural history of the disease so far. Summary: In this review, we will go through the role of surgery in the management of $C D$, showing the potential benefits of an early surgical approach as well as the
\end{abstract}

karger@karger.com www.karger.com/iid

Karger!
(C) 2021 The Author(s)

Published by S. Karger AG, Basel

This is an Open Access article licensed under the Creative Common Attribution-NonCommercial-4.0 International License (CC BY-NC) (http://www.karger.com/Services/OpenAccessLicense), applicable to the online version of the article only. Usage and distribution for commercial purposes requires written permission. impact of surgical research in the natural history of the disease. From this standpoint, we will show the role of different anastomotic configurations, emphasizing how more and more data are definitively establishing the impact of the novel Kono-S anastomosis in reducing endoscopic and surgical recurrence. Mesentery-based surgery is a novel and appealing surgical perspective, but more data are required. Key Messages: Surgery has demonstrated to be a crucial tool in the therapeutic armamentarium for the management of CD. Early surgery and novel surgical techniques, such as the Kono-S anastomosis, may have an impact on the natural history of the disease, including the possibility to prevent recurrences.

(c) 2021 The Author(s). Published by S. Karger AG, Basel

\section{Introduction}

Since Crohn's disease (CD) was first described, its relationship with surgery has been sometimes conflictual, and the landmark article published in JAMA in 1932 is quite iconic [1]. Fourteen patients were reported being affected by the so-called "regional ileitis" for whom surgi- 
cal resection of the involved intestinal tract was considered as the only therapeutic viable road. Nevertheless, the surgeon who performed those procedures was not included in the authorship list (Dr. A.A. Berg, Mount Sinai Hospital, New York, NY, USA), and the disease was named by Dr. B. B. Crohn, an eminent internist. Doing a time flight of about 90 years, the role of surgery still seems muted as recommended in an authoritative review published by Torres et al. [2] in The Lancet. In fact, the authors proposed a therapeutic algorithm in which the word "surgery" was not contemplated while in the text they dedicated only a quarter of a page to surgical indications, limited to medical therapy failure and obstructive phenotype of the disease. Willing to make a comparison, surgery could be seen as a "Cinderella" in CD fairytale.

Even though it is unquestionable that surgery rates decreased during the last 2 decades, a meta-analysis showed that the risk of surgery at 1,5 , and 10 years after diagnosis of CD was $16.3,33.3$, and $46.6 \%$, respectively, and up to $48 \%$ of these patients will be in need of multiple surgeries due to recurrences, despite modern biological therapies and medical optimization [3-5]. Furthermore, an endoscopic/sonographic-based risk matrix model to predict 1-year risk of surgery for severe/refractory CD patients has been recently developed [6]. According to Rispo et al. [6], Simple Endoscopic Score for Crohn's Disease (SESCD) $\geq 9$, bowel wall thickening $\geq 7 \mathrm{~mm}$, small bowel CD extension at bowel sonography $\geq 33 \mathrm{~cm}$, and stricturing/ penetrating behavior were the only independent factors predictive of surgery at 1 year.

Bearing this in mind, the question spontaneously arises: What can surgeons do to have an impact on the natural history of CD? In other words, is it time for Cinderella to become a princess?

\section{Surgery-First Approach}

In order to support a "surgery-first approach," longterm studies demonstrated that there is a $50 \%$ chance of not requiring any further operation for $\mathrm{CD}$ after primary ileocecal resection $[7,8]$. The idea of an early surgery has been debated for a long time: the issue is whether to consider surgery to be the "last resort" when any other medical options have failed, a part of a multimodal strategy, or even an alternative to long-term medical therapy [911]. Considering that surgery for primary disease is technically easier and has lower complication rates compared with surgery for recurrent disease and after immunosuppressant therapy, this latter possibility is even more captivating. The main problem in implementing early surgery in clinical practice has been the lack of prospective and randomized data. From this standpoint, results from the LIR!C trial provided crucial insights [12]. This study demonstrated that laparoscopic ileocecal resection is a safe alternative to infliximab in case of localized $(<40 \mathrm{~cm})$ inflammatory terminal ileitis after the failure of conventional therapy. Patients who were nonresponsive to corticosteroids, thiopurines, or methotrexate were enrolled in this randomized, controlled, multicenter, open-label trial. The primary outcome was 1-year quality of life based on the evaluation of the Inflammatory Bowel Disease Questionnaire (IBDQ), 12 months after treatment. Secondary outcomes took into account items like general quality of life, assessed with the Short Form-36 (SF-36), including its physical and mental domains, days of inability to participate in social life, and esthetic results. In the LIR!C study, laparoscopic ileocecal resection, although not superior, appeared to be similar to infliximab treatment in terms of restoring the quality of life (mean IBDQ: 178 vs. 172 at 12 months) and not associated with significantly increased morbidity. More, long-term follow-up reveals that more than one-third of patients in the infliximab group will require surgery anyway after 70 weeks, whereas only a quarter of patients who received resection will need anti-TNF medical therapy within 112 weeks. Recently, retrospective long-term follow-up results of this trial were published [13]; in detail, data were collected from 134 (94\%) of 143 patients previously included in the trial, of whom 69 underwent resection and 65 received infliximab. After a median follow-up of 63.5 months, 18 (26\%) patients belonging to the resection group started anti-TNF therapy and no one required a second resection. Twenty-nine patients in the resection group did not receive any additional $\mathrm{CD}$-related medication, although $14(48 \%)$ of these patients were given prophylactic immunomodulator therapy. On the other hand, 31 (48\%) patients of the infliximab group had a CD-related resection, and the remaining 34 patients maintained, switched, or escalated their anti-TNF therapy.

\section{Conventional Anastomosis}

In the last decade, a common challenge has been to define whether any role is played by the anastomotic configuration to reduce recurrences for $\mathrm{CD}$. To date, there is still a lack of clear consensus regarding the best anastomotic technique after ileocolic resection for CD; in fact, no anastomotic technique has previously demonstrated a clear advantage in terms of preventing recurrences [14].

With the assumption that stapled side-to-side anastomosis may create physiological alteration of the intestinal function from transection of the circular muscular layer
Luglio/Kono 
and antiperistaltic configuration (independently from $\mathrm{CD}$ recurrence), Gajendran et al. [15] ran a single-center prospective observational study in which $128 \mathrm{CD}$ patients undergoing surgical resection were enrolled, comparing side-to-side and end-to-end anastomoses. Primary outcomes evaluated 2-year postoperative healthcare utilization (measured by proportion of patients who had emergency department visit, hospitalization, abdominal imaging, and repeat bowel resection due to CD-related reasons) and quality of life. Results highlighted that side-to-side patients showed higher rates of emergency department visits ( 33.3 vs. $14.7 \% ; p=0.01$ ), hospitalizations (30 vs. $11.8 \% ; p=0.01)$, and abdominal computed tomography scans (50 vs. $13.2 \%$; $p<0.001$ ) with lower QoL (mean short inflammatory bowel disease questionnaire 47.9 vs. 53.4; $p=0.007)$. Moreover, there was no difference among the 2 groups in the 30 -day surgical complications and 2 -year patterns of disease activity, CD medication requirement, endoscopic recurrence, and need for new surgical management (all $p>0.05$ ) [15]. An additional concern regarding the stapled side-to-side anastomosis comes from some endoscopists that emphasize how this anastomosis can be sometimes difficult to scope, because of a kind of U-turn shape that is created between the colon and the ileum, other than for the "pouch-like" configuration of the anastomosis itself.

By contrast, ECCO/ESCP consensus on Surgery for Crohn's Disease is in favor of a wide lumen stapled sideto-side (functional end-to-end) anastomosis, and 3 metaanalyses support this statement [16]. In the first one by Simillis et al. [17], 661 patients were included, and the anastomotic leak rate resulted higher for the end-to-end anastomosis versus side-to-side anastomosis (OR 4.37; $p=0.02$ ). Moreover, overall postoperative complications (OR 2.64; $p<0.001$ ) and length of hospital stay were accordingly higher (by 2.81 days; $p=0.007$ ) when an endto-end anastomosis was performed. A later meta-analysis by Guo et al. [18] confirmed the superiority of a side-toside anastomosis over other configurations in terms of overall postoperative complications (OR $0.6 ; p=0.01$ ) but failing to demonstrate statistically significant differences regarding leak rate, endoscopic and clinical recurrence, and reoperation for recurrence. A further meta-analysis by He et al. [19] compared 396 stapled side-to-side with 425 handsewn end-to-end anastomoses. Stapled side-toside fashion was superior in all endpoints: overall postoperative complications (OR 0.54, 95\% CI: 0.32-0.93), anastomotic leak (OR 0.45, 95\% CI: 0.20-1.00), recurrence (OR 0.20, 95\% CI: 0.07-0.55), and reoperation for recurrence (OR 0.18, 95\% CI: 0.07-0.45). Finally, a network

Preventing Surgical Recurrences in Crohn's Disease meta-analysis of 11 trials and 1,113 patients confirmed the superiority of stapled side-to-side anastomosis in terms of overall complications, clinical recurrence, and reoperation for recurrence. Leak rate, surgical site infections, mortality, and length of stay were not affected by the choice of the anastomosis technique [20]. After all, it must be highlighted that just a minority of patients were included in RCTs resulting in a low quality of the studies included in all meta-analyses.

As for other evidences, the choice of a stapled side-toside anastomosis found moderate agreement in the 2015 Think Tank on CD surgery of the Italian Society of Colorectal Surgery (SICCR) ("Agree" 62.5\%) [21]. Furthermore, a recent "position statements" by the same society supports again the use a wide lumen stapled side to side (functional end-to-end) as the preferred anastomotic technique to be fashioned after ileocolic resection, on the light of current evidence [22].

\section{Surgical Prophylaxis}

Even if it is true that the anastomosis is often the site of postoperative recurrence, it must be said that additional recurrence sites have been also described far from the anastomosis. Fichera et al. [23], for example, carried out a retrospective study on a prospective maintained database, reporting that around one-third of surgical recurrences involve bowel tracts far from the primary anastomosis: in detail, duodenum (1\%), jejunum/ileum (34\%), terminal ileum/neoterminal ileum (42\%), and colon/rectum $(23 \%)$.

Nevertheless, from a surgical perspective, the perpetual will to positively impact the clinical history of these patients, preventing recurrences at the anastomotic sites, opened the doors to the ideation of a novel type of anastomosis: the Kono-S anastomosis (Fig. 1). Kono-S anastomosis is defined as a handsewn antimesenteric functional end-to-end anastomosis. The mesentery of the intestinal segment to be excised is divided at the mesenteric edge of the bowel wall by the use of a vesselsealing system to avoid an unnecessary devascularization and denervation of residual bowel and to maintain adequate blood supply and neural control to the anastomotic site. The intestine is transected by use of a linear staple cutter such that the mesenteric side was located in the center of the stump, at a $90^{\circ}$ angle to the mesentery. Both ends of the stump were reinforced with $3 / 0$ braided polyglycolide lactide (Vicryl). Before the anastomosis, the stumps were sutured by 4 or 5 stitches together to create a supporting column (Fig. 1a); hence, the name Kono-S, as in supporting, which would maintain orientation and 


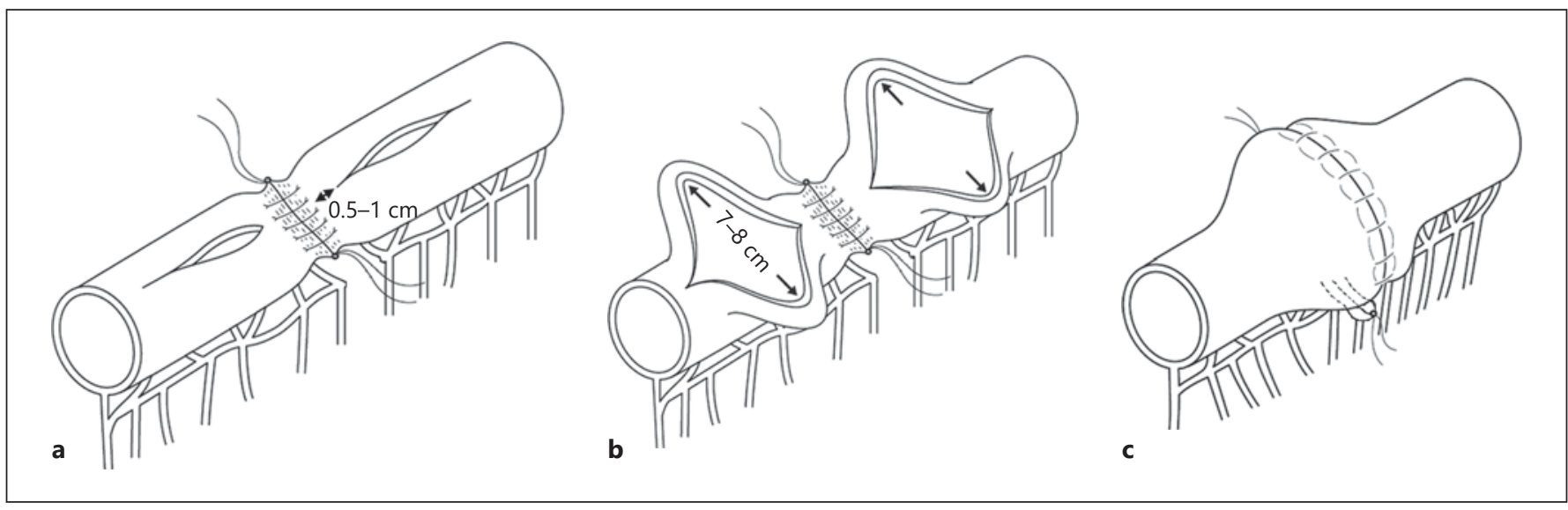

Fig. 1. Kono-S anastomosis. a An antimesenteric longitudinal enterotomy (or colostomy) is performed on each stump, starting no $>1 \mathrm{~cm}$ but no $<0.5 \mathrm{~cm}$ away from the supporting column (both ends arrow). $\mathbf{b}$ A transverse lumen of $7 \mathrm{~cm}$ on the small bowel or closer to $8 \mathrm{~cm}$ on the colon. c Completion of the Kono-S anasto- mosis. The supporting column is located immediately behind the posterior wall of the anastomosis. The supporting column provides stable support that will prevent mechanical deformation and functional constriction of the lumen of the anastomosis. the large lumen diameter of the anastomosis. Longitudinal enterotomies of approximately $7-8 \mathrm{~cm}$ are then performed to achieve a transverse lumen on the antimesenteric side, $0.5-1 \mathrm{~cm}$ from the supporting column to maximize the supporting effect of the column on the anastomosis (Fig. 1a, b). The anastomosis is then created transversely in handsewn fashion with a single or twolayer 3/0 Vicryl running sutures, which thus result in a large anastomosis [24]. This results in a large anastomosis. Moreover, the supporting column is located immediately behind the posterior wall of the anastomosis (Fig. 1c), providing a rigid and stable support to prevent mechanical deformation and functional constriction of the lumen of the anastomosis like as a "back bone" of the anastomosis.

\section{Results from Early Studies regarding This Novel Type of Anastomosis Are Encouraging}

Kono et al. [25] performed Kono-S anastomosis in 69 CD patients from 2003 to 2009 and compared this group with a historical cohort of $73 \mathrm{CD}$ patients who underwent conventional anastomosis from 1993 to 2003. It was found significantly lower endoscopic recurrence rates in the Kono group than in the conventional one, with a lower probability of anastomotic surgical recurrence in the Kono group after 5 years ( 0 vs. 15\%; $p<0.0013$ ), and these results were independent from the use of biologics in the perioperative period. Therefore, no patient with the Kono-S anastomosis presented a surgical recurrence. The drawback of this first report lays in its not randomized retrospective design: moreover, the control group is an historical cohort. Similar results were then confirmed by a larger multicenter study in which 187 patients in Japan (144 patients, group J) and USA (43 patients, group US) who received the Kono-S anastomosis were included [26].

The 5-year surgical recurrence-free rate was $98.6 \%$, and the 10-year surgical recurrence-free rate was also $98.6 \%$ in group J. In the US group, no surgical recurrence has occurred during the follow-up period of 32 months. The 5-year cumulative surgical recurrence rate was $1.8 \%$ (95\% CI: $0-4.3 \%$ ), and the 10-year cumulative surgical recurrence rate was also $1.8 \%$ (95\% CI: $0-4.3 \%$ ) in group J. The 5-year cumulative surgical recurrence rate was $1.7 \%$ (95\% CI: $0-4.2 \%$ ), and the 10 -year cumulative surgical recurrence rate was also $1.7 \%$ (95\% CI: $0-4.2 \%)$ in cumulative experience. Unfortunately, this study has some notable limitations too, again it is a nonrandomized retrospective study with a relatively small sample size and a shorter follow-up of the US group.

In their single-center retrospective nonrandomized study, Shimada et al. [27] compared the Kono-S anastomosis to the handsewn end-to-end anastomosis. With regard to long-term outcomes, Kaplan-Meier analysis showed a lower probability of a second surgery at the anastomosis site in the Kono group than in the end-toend one. The 5-year surgery-free survival rate at the anastomosis site was significantly higher with the Kono-S anastomosis (95.0\% [95\% CI: 0.90-1.00]) than that with the end-to-end anastomosis (81.3\% [95\% CI: 0.73-0.89]). 
Table 1. Current evidence on Kono-S anastomosis

\begin{tabular}{|c|c|c|c|c|c|}
\hline Authors & Year & Countries & Study design & Patients, $n$ & Brief Kono-S results \\
\hline Kono et al. [25] & 2011 & Japan & $\begin{array}{l}\text { Comparative with } \\
\text { historical cohort }\end{array}$ & 142 (69 Kono-S) & $\begin{array}{l}\text { Median Rutgeerts score in Kono-S group: } 2.6 \\
\text { Median Rutgeerts score in control group: } 3.4\end{array}$ \\
\hline Kono et al. [29] & 2016 & Japan, USA & Case series & 187 & $\begin{array}{l}\text { Group J: } 2 \text { surgical anastomotic recurrences (median } \\
\text { follow-up of } 65 \text { months) } \\
\text { Group US: } 0 \text { surgical anastomotic recurrences (median } \\
\text { follow-up of } 32 \text { months) }\end{array}$ \\
\hline Shimada et al. [27] & 2018 & Japan & $\begin{array}{l}\text { Comparative with } \\
\text { historical cohort }\end{array}$ & 215 (117 Kono-S) & $\begin{array}{l}\text { Surgical recurrence in } 4 \text { patients }(3.4 \%) \text { in the Kono-S } \\
\text { group and } 24(24.4 \%) \text { in the end-to-end group }\end{array}$ \\
\hline Seyfried et al. [30] & 2019 & Germany & Case series & 53 & No anastomotic recurrence was detected \\
\hline Luglio et al. [28] & 2020 & Italy & RCT & 79 (36 Kono-S) & $\begin{array}{l}\text { Overall postoperative recurrence in Kono group versus } \\
\text { side-to-side group: } 22.2 \text { versus } 62.8 \% \\
\text { Severe postoperative endoscopic recurrence in Kono } \\
\text { group versus side-to-side group: } 13.8 \text { versus } 34.8 \%\end{array}$ \\
\hline Katsuno et al. [31] & 2015 & Japan & Case series & 30 & $\begin{array}{l}\text { Mean Rutgeerts score: } 0.7(0-3) \\
\text { Median follow-up: } 14.8 \text { months }(3-37) \text { (for } 19 \text { patients) }\end{array}$ \\
\hline Krane et al. [32] & 2015 & USA & Case series & 96 & $\begin{array}{l}\text { Mean Rutgeerts score: } 0.71(0-3) \\
\text { Mean follow-up: } 22.8 \text { months (3.0-53.9) (for } 62 \text { patients) }\end{array}$ \\
\hline Fichera et al. [33] & 2012 & Japan, Italy & Case series & 44 & $\begin{array}{l}\text { Mean Rutgeerts score: } 0.72(0-3) \\
\text { Mean follow-up: } 6.8 \text { months (for } 18 \text { patients) }\end{array}$ \\
\hline
\end{tabular}

Moreover, only 4 patients (3.4\%) in the Kono group underwent a second surgery after a mean of 47.3 months (IQR, 31-66), while 24 (24.4\%) patients in the end-to-end group underwent such a second surgery after a mean of 99 months (IQR, 64-115). More than 1 year after surgery, 21 patients developed surgical recurrence at the anastomosis site. During this period, the use of Kono-S anastomosis resulted as a protective factor from the risk of surgical recurrence (OR, 0.08 ; 95\%CI: $0.02-0.33$; $p<0.001$ ) [27]. As for the previous ones, the design of this study is its main limitation, in addition to the absence of endoscopic recurrence evaluation; the leak rate in the standard group (17.3 vs. $5.1 \%$ ) seems to be higher compared to data usually reported from the literature and might be a further aspect that biased results.

Aiming to overcome these limitations, the SupremeCD study [28] was designed. A total of 79 CD patients were randomized in the "Kono-S group" (36 patients) and in the "conventional group" (43 patients); in this latter group, patients received the conventional side-to-side antiperistaltic anastomosis (functional end-to-end). After 6 months, $22.2 \%$ in the Kono group and $62.8 \%$ in the conventional group presented an endoscopic recurrence $(p<0.001$, odds ratio [OR] 5.91). A severe postoperative endoscopic recurrence (Rutgeerts score $\geq i 3$ ) was found in
$13.8 \%$ of Kono versus $34.8 \%$ of conventional group patients ( $p=0.03$, OR 3.32). Clinical recurrence rate was $8 \%$ in the Kono group versus $18 \%$ in the conventional group after 12 months $(p=0.2)$ and 18 versus $30.2 \%$ after 24 months ( $p=0.04$, OR 3.47). Surgical recurrence rate after 24 months was $0 \%$ in the Kono group versus $4.6 \%$ in the conventional group $(p=0.3)$. Patients with Kono-S anastomosis presented a longer time until clinical recurrence than patients with side-to-side anastomosis (hazard ratio $0.36, p=0.037)$. Moreover, on binary logistic regression analysis, the Kono-S anastomosis was the only variable significantly associated with a reduced risk of endoscopic recurrence (OR $0.19, p<0.001$ ) [28]. A summary of the current evidence on Kono-S anastomosis is available in Table 1, emphasizing the main results from all the studies published to date [25, 27-33].

The surgical technique itself and configuration of the Kono-S anastomosis could pathophysiologically explain these results: the supporting column preserves the feature and diameter of the anastomosis, in order to avoid distortions and strictures associated with recurrent diseases at the anastomotic site, especially on the mesenteric side which is identified as the original site of anastomotic CD recurrence. Further benefits of this innovative surgical technique include the preservation of blood stream and 
innervation, both factors associated with high risk of anastomotic recurrence in CD [34]. A larger multicenter randomized trial (NCT03256240) is currently ongoing, recruiting patients from USA and Europe, which will hopefully give an end to the story, fully establishing the role of the Kono-S anastomosis in impacting the natural history of CD.

With regard to the role of surgery in influencing the natural history of CD, a "mesentery-based" surgery is gaining appraisal [35]. A recent study by Coffey et al. [36] demonstrated, for the first time, that the inclusion of the mesentery as part of intestinal resection is associated with reduced surgical recurrence. The authors compared surgical recurrence in 2 cohorts: in cohort A (30 patients), a standard ileocecal resection was performed, cutting the mesentery close to the bowel wall; in cohort B (34 patients), the mesentery supplying the ileocecal affected segment was fully mobilized and resected together with the bowel. The cumulative reoperation rate in cohort $\mathrm{A}$ was $40 \%$, while it was only $2.9 \%$ in cohort B. Most of the recurrences happened within 2 years after surgery. Mesentery-sparing resection was, therefore, recognized as an independent risk factor for surgical recurrence. Coffey et al. [36] also developed a novel "mesenteric disease activity index" based on the presence of "fat wrapping" and "mesenteric thickening": other than being related to the Crohn's Disease Activity Index (CDAI) and to the percentage of circulating fibrocytes, it was also found to pre- dict surgical recurrence. Despite the great interest of Coffey's idea, the absence of randomized data and clear biases in the study design certainly advocate the need of prospective and well-designed studies to definitively assess the role of the mesentery in preventing recurrences in $\mathrm{CD}$.

\section{Conclusions}

Even though novel clinical trials are certainly necessary to fully address current hot topics and unmet needs in CD treatment, all these data make us feel ready to answer the provocative question we have raised in the beginning: yes, it is time for Cinderella to become a princess.

\section{Conflict of Interest Statement}

The authors declare no conflicts of interest regarding this publication.

\section{Author Contributions}

Both the authors have contributed to the conception of the work, data collection and interpretation, drafting of the manuscript, critical revision, and final approval.

\section{References}

1 Crohn BB, Ginzburg L, Oppenheimer GD. Landmark article Oct 15, 1932. Regional ileitis. A pathological and clinical entity. By Burril B. Crohn, Leon Ginzburg, and Gordon D. Oppenheimer. JAMA. 1984;251(1):73.

2 Torres J, Mehandru S, Colombel JF, PeyrinBiroulet L. Crohn's disease. Lancet. 2017; 389(10080): 1741 .

3 Frolkis AD, Dykeman J, Negrón ME, Debruyn J, Jette N, Fiest KM, et al. Risk of surgery for inflammatory bowel diseases has decreased over time: a systematic review and meta-analysis of population-based studies. Gastroenterology. 2013;145(5):996-1006.

4 Frolkis AD, Lipton DS, Fiest KM, Negrón ME, Dykeman J, Debruyn J, et al. Cumulative incidence of second intestinal resection in Crohn's disease: a systematic review and meta-analysis of population-based studies. Am J Gastroenterol. 2014;109:1739-48.
5 Shinagawa T, Hata K, Ikeuchi H, Fukushima K, Futami K, Sugita A, et al. Rate of reoperation decreased significantly after year 2002 in patients with Crohn's disease. Clin Gastroenterol Hepatol. 2020.

6 Rispo A, Imperatore N, Testa A, Bucci L, Luglio G, De Palma GD, et al. Combined endoscopic/sonographic-based risk matrix model for predicting one-year risk of surgery: a prospective observational study of a tertiary centre severe/refractory crohn's disease cohort. J Crohns Colitis. 2018;12:784-93.

7 Weston LA, Roberts PL, Schoetz DJ Jr, Coller JA, Murray JJ, Rusin LC. Ileocolic resection for acute presentation of Crohn's disease of the ileum. Dis Colon Rectum. 1996;39(8): 841-6.

8 Kim NK, Senagore AJ, Luchtefeld MA, MacKeigan JM, Mazier WP, Belknap K, et al. Longterm outcome after ileocecal resection for Crohn's disease. Am Surg. 1997;63(7):62733.
9 Krause U. Early or late operation in the treatment of Crohn's disease [Internet]. Scand J Gastroenterol. 1971;6(6):479-81 [cited 2018 Sept 12]. Available from: http://www.ncbi. nlm.nih.gov/pubmed/4399325.

10 Latella G, Caprilli R, Travis S. In favour of early surgery in Crohn's disease: a hypothesis to be tested [Internet]. J Crohns Colitis. 2011 Feb;5(1):1-4 [cited 2018 Sept 12]. Available from:

11 Bemelman WA, Allez M. The surgical intervention: earlier or never? [Internet]. Best Pract Res Clin Gastroenterol. 2014 Jun;28(3): 497-503 [cited 2018 Sept 12]. Available from: http: //linkinghub.elsevier.com/retrieve/pii/ S1521691814000572.

12 Ponsioen CY, de Groof EJ, Eshuis EJ, Gardenbroek TJ, Bossuyt PMM, Hart A, et al. Laparoscopic ileocaecal resection versus infliximab for terminal ileitis in Crohn's disease: a randomised controlled, open-label, multicentre trial. Lancet Gastroenterol Hepatol. 2017. 
13 Stevens TW, Haasnoot ML, D'Haens GR, Buskens CJ, de Groof EJ, Eshuis EJ, et al. Laparoscopic ileocaecal resection versus infliximab for terminal ileitis in Crohn's disease: retrospective long-term follow-up of the LIR!C trial. Lancet Gastroenterol Hepatol. 2020;5:900-7.

14 SICCR Current Status of Crohn's Disease Surgery Collaborative. National variations in perioperative assessment and surgical management of Crohn's disease: a multicentre study. Colorectal Dis. 2020;23:94-104.

15 Gajendran M, Bauer AJ, Buchholz BM, Watson AR, Koutroubakis IE, Hashash JG, et al. Ileocecal anastomosis type significantly influences long-term functional status, quality of life, and healthcare utilization in postoperative Crohn's disease patients independent of inflammation recurrence. Am J Gastroenterol. 2018;113:576-83.

16 Bemelman WA, Warusavitarne J, Sampietro GM, Serclova Z, Zmora O, Luglio G, et al. ECCO-ESCP consensus on surgery for Crohn's disease. J Crohns Colitis. 2018;12:1-16.

17 Simillis C, Purkayastha S, Yamamoto T, Strong SA, Darzi AW, Tekkis PP. A metaanalysis comparing conventional end-to-end anastomosis vs. other anastomotic configurations after resection in Crohn's disease. Dis Colon Rectum. 2007;50(10):1674-87.

18 Guo Z, Li Y, Zhu W, Gong J, Li N, Li J. Comparing outcomes between side-to-side anastomosis and other anastomotic configurations after intestinal resection for patients with Crohn's disease: a meta-analysis. World J Surg. 2013.

19 He X, Chen Z, Huang J, Lian L, Rouniyar S, Wu X, et al. Stapled side-to-side anastomosis might be better than handsewn end-to-end anastomosis in ileocolic resection for Crohn's disease: a meta-analysis. Dig Dis Sci. 2014; 59(7):1544-51.
20 Feng J-S, Li J-Y, Yang Z, Chen X-Y, Mo J-J, Li $\mathrm{S}-\mathrm{H}$. Stapled side-to-side anastomosis might be benefit in intestinal resection for Crohn's disease: a systematic review and network meta-analysis. Medicine. 2018;97:e0315.

21 Pellino G, Selvaggi F, Ghezzi G, Corona D, Riegler G, Delaini GG. A think tank of the Italian society of colorectal surgery (SICCR) on the surgical treatment of inflammatory bowel disease using the Delphi method: Crohn's disease. Tech Coloproctol. 2015;19: 639-51.

22 Pellino G, Keller DS, Sampietro GM, Angriman I, Carvello M, Celentano V, et al. Inflammatory bowel disease position statement of the Italian Society of Colorectal Surgery (SICCR): Crohn's disease. Tech Coloproctol. 2020;24:397-419.

23 Fichera A, Lovadina S, Rubin M, Cimino F, Hurst RD, Michelassi F. Patterns and operative treatment of recurrent Crohn's disease: a prospective longitudinal study. Surgery. 2006; 140:649-54.

24 Luglio G, Tropeano FP, Amendola A, Rispo A, Castiglione F, Bucci L, et al. Preventing recurrence in Crohn's disease: the Kono-S anastomosis with two-layer technique. Tech Coloproctol. 2020;24(11):1213-4.

25 Kono T, Ashida T, Ebisawa Y, Chisato N, Okamoto K, Katsuno H, et al. A new antimesenteric functional end-to-end handsewn anastomosis: surgical prevention of anastomotic recurrence in Crohn's disease. Dis Colon Rectum. 2011;54:586-92.

26 Kono T, Fichera A, Maeda K, Sakai Y, Ohge $\mathrm{H}$, Krane $\mathrm{M}$, et al. Kono-S anastomosis for surgical prophylaxis of anastomotic recurrence in Crohn's disease: an international multicenter study. J Gastrointest Surg. 2016; 20:783-90.

27 Shimada N, Ohge H, Kono T, Sugitani A, Yano R, Watadani Y, et al. Surgical recurrence at anastomotic site after bowel resection in Crohn's disease: comparison of Kono-S and end-to-end anastomosis. J Gastrointest Surg. 2019.
28 Luglio G, Rispo A, Imperatore N, Giglio MC, Amendola A, Tropeano FP, et al. Surgical prevention of anastomotic recurrence by excluding mesentery in Crohn's disease: the SuPREMe-CD study: a randomized clinical trial. Ann Surg. 2020;272:210-7.

29 Kono T, Fichera A, Maeda K, Sakai Y, Ohge $\mathrm{H}$, Krane M, et al. Kono-S anastomosis for surgical prophylaxis of anastomotic recurrence in Crohn's disease: an international multicenter study. J Gastrointest Surg. 2016; 20(4):783-90.

30 Seyfried S, Post S, Kienle P, Galata CL. Die Kono-S-Anastomose in der Chirurgie des Morbus Crohn. Der Chir. 2019.

31 Katsuno H, Maeda K, Hanai T, Masumori K, Koide Y, Kono T. Novel antimesenteric functional end-to-end handsewn (kono-s) anastomoses for Crohn's disease: a report of surgical procedure and short-term outcomes. Dig Surg. 2015;32:39-44.

32 Krane MK, Cannon LM, Allaix ME, Kono T, Fichera A. A new antimesenteric functional end-to-end handsewn (Kono-S) anastomosis: feasibility and short-term outcomes in Crohn's disease. J Am Coll Surg. 2015.

33 Fichera A, Zoccali M, Kono T. Antimesenteric functional end-to-end handsewn (Kono-S) anastomosis. J Gastrointest Surg. 2012;16(7): 1412-6.

34 Peltrini R, Greco PA, Manfreda A, Luglio G, Bucci L. Kono-S anastomosis after intestinal resection for Crohn's disease. Updates Surg. 2020;72:335-40.

35 Peltrini R, Bucci L. "Mesentery-based surgery" to prevent surgical recurrence in Crohn's disease: from basics to surgical practice. Int J Colorectal Dis. 2019;34:353-4.

36 Coffey CJ, Kiernan MG, Sahebally SM, Jarrar A, Burke JP, Kiely PA, et al. Inclusion of the mesentery in ileocolic resection for Crohn's disease is associated with reduced surgical recurrence. J Crohns Colitis. 2018;12:1139-50. 